\title{
ANÁLISES DE PARABENOS EM PRODUTOS COSMÉTICOS EMPREGANDO A CROMATOGRAFIA EM CAMADA DELGADA E TITULAÇÃO POTENCIOMÉTRICA
}

\author{
Thalia Nunes Batista ${ }^{1}$, Taís Arthur Corrêa $a^{2}$, Natália Cristina da Silva ${ }^{l}$, Lidervan de Paula Melo ${ }^{1 *}$, \\ ${ }^{1}$ Departamento de Ciências Exatas e da Terra, Universidade do Estado de Minas Gerais (UEMG), CEP 36502000, Ubá, MG, Brasil. \\ ${ }^{2}$ Departamento de Ciências Exatas e da Terra, Universidade do Estado de Minas Gerais (UEMG), CEP 38200000, Frutal, MG, \\ Brasil.
}

*E-mail: lidervan.melo@uemg.br

\section{RESUMO}

Os parabenos são conservantes químicos utilizados em diversos produtos, dentre eles, os cosméticos. Estes compostos aumentam o tempo de vida útil dos produtos e evitam o desenvolvimento de fungos e bactérias, podendo ser adicionados individualmente ou em misturas, aumentando a atividade contra a ação de microorganismos patogênicos. O uso de parabenos em cosméticos precisa ser monitorado devido ao caráter lipofílico que, em altas concentrações, podem acumular nos tecidos do corpo humano ou também induzir dermatites alérgicas. Para garantir a segurança dos consumidores, o objetivo deste trabalho foi realizar a análise de parabenos em amostras de cosméticos, empregando cromatografia em camada delgada e titulação potenciométrica. O eluente selecionado para a cromatografia foi diclorometano: metanol $(98: 2, \mathrm{v} / \mathrm{v})$. Na etapa de preparo de amostra foi realizada uma extração sólido-líquida. Diferentes solventes para a extração dos parabenos foram avaliados: etanol 100\%, etanol: água (50:50, v/v) e solução aquosa acidificada (água: ácido acético $1 \%(\mathrm{v} / \mathrm{v})$. A titulação potenciométrica foi realizada empregando pHmetro digital de bancada e $\mathrm{H}_{2} \mathrm{SO}_{4} \operatorname{como}$ titulante.Foram analisadas cinco amostras, segundo os resultados obtidos, empregando a titulação potenciométrica. Duas amostras não apresentaram nenhum conservante, uma apresentou apenas metil e duas continham metil e propil-parabenos. Também foi possível constatar que as amostras que continham parabenos estavam dentro dos valores preconizados pela ANVISA. A precisão inter-ensaio foi avaliada resultando em coeficiente de variação menor que 5,0\% para todas as amostras. O método desenvolvido apresentou-se com uma ferramenta simples e acessível que utiliza menor volume de solvente orgânico e pode ser aplicado no controle de qualidade de conservantes em cosméticos.

Palavras-chave: Cosméticos. Parabenos. Cromatografia. Titulação. Conservantes.

\section{Introdução}

Os parabenos foram introduzidos pela primeira vez na década de 1920 e atualmente está entre os conservantes mais empregados não só em cosméticos, mas também em fármacos e alimentos [1]. Esses compostos atendem a vários pré-requisitos para a conservação de um produto, tais como: baixo custo, amplo espectro de atividade antimicrobiana, biodegradabilidade, estabilidade a mudanças de $\mathrm{pH}$ e ausência de cor e cheiro. Sua eficácia varia de acordo com o número de carbonos do grupo substituinte ligado ao grupo éster na molécula de parabeno, uma vez que quanto maior o comprimento do grupo alquílico maior sua eficiência, no entanto, menor a solubilidade em água [2-3].

Embora a utilização desses conservantes apresente muitas vantagens, seu uso começou a ser questionado em 1998, quando
Routledge e colaboradores [4] apresentaram indícios de propriedades xenoestrogênicas em relação a esses compostos, mas o que acentuou a problemática do uso de parabenos foi um estudo realizado por Darbreet al [5] onde foi encontrado parabenos em tecidos de tumores de câncer de mama. A toxicidade dos parabenos está diretamente ligada ao seu caráter lipofílico e devido a seu baixo peso molecular são rapidamente absorvidos, tendendo a se acumular nos tecidos gordurosos da pele, podendo atuar como desreguladores endócrinos [6-7].

O uso de parabenos em amostras de cosméticos tem sido regulado em todo o mundo [8]. No Brasil, a Agência Nacional de Vigilância Sanitária (ANVISA), através da Resolução RDC n 29 , de 01 de junho de 2012, republicada no D.O. de 04/06/2012, estabelece as concentrações máximas permitidas para o ácido 4hidroxibenzóico, seus sais e ésteres de $0,4 \%(\mathrm{~m} / \mathrm{m})$ adicionado 
individualmente e $0,8 \%(\mathrm{~m} / \mathrm{m})$ para misturas de dois ou mais parabenos. Essa resolução é baseada na legislação 76/768/EEC, anexo VI, parte 1, referência 12 da Comunidade Europeia (EuropeanCommunitties, 1976) [5].

A cromatografia é um processo físico-químico que permite a separação, identificação e quantificação de compostos em uma mistura homogênea. A cromatografia em camada delgada (CCD) baseia-se na adsorção dos compostos com a fase estacionária por interações físicas como ligações de hidrogênio e do tipo dipolo-dipolo. Esta técnica tem sido amplamente utilizada para identificação de compostos orgânicos e monitoramento de reações químicas. $\mathrm{Na} \mathrm{CCD}$ a fase estacionária, constituída por um material de alumínio, é revestida de adsorvente geralmente a sílica. Após a eluição dos analitos na placa cromatográfica emprega-se um método de revelação dos compostos permitindo a identificação dos analitos mediante comparação com padrões analíticos [9-10].

Para quantificação de parabenos em matérias-primas as Farmacopeias dos Estados Unidos, brasileira e britânica preconizam a titulação potenciométrica e a Cromatografia Líquida de Alta Eficiência (CLAE) para análises [11-12]. Neste trabalho um método analítico de baixo custo e preciso foi desenvolvido empregando a CCD e a titulação potenciométrica para análises de parabenos em amostras de cosméticos.

\section{Metodologia}

\subsection{Preparo de amostra}

As amostras de cosméticos foram adquiridas nos comércios locais da cidade de Ubá/MG e foram considerados a data de validade das amostras e o tipo de cosméticos (creme, hidratante ou emulsão), assim como as informações contidas nos rótulos sobre a presença ou não dos parabenos. Foi selecionado um total de cinco amostras, onde duas delas apresentam na descrição de seus rótulos a presença de metil e propilparabeno, uma somente com metilparabeno e as demais não constam a descrição da presença de parabenos nos rótulos.

Visando obter uma melhor eficiência de extração dos analitos e diminuir os compostos interferentes da matriz, os seguintes solventes para a extração dos parabenos foram avaliados: etanol 100\%, etanol: água (50:50, v/v) e solução aquosa acidificada (água: ácido acético $1 \%$ (v/v).

Após selecionado o melhor extrator, pesou-se 1,0 g de amostra, adicionou 10,0 $\mathrm{mL}$ do solvente e, em seguida, centrifugou-se por 20 minutos. O sobrenadante foi coletado para dar prosseguimento às análises.

\subsection{Identificação dos parabenos por CCD}

A identificação dos parabenos nas amostras foi realizada através da CCD (placa cromatográfica marca MACHEREYNAGEL) a qual foi recortada em $6,5 \mathrm{~cm}$ por $4,0 \mathrm{~cm}$ de largura. $\mathrm{O}$ material adsorvente foi à base de sílica $\left(\mathrm{SiO}_{2}\right)$. Tendo em vista uma melhor separação cromatográfica, foram avaliadas as fases móveis: diclorometano $100 \%$ e diclorometano:metanol nas proporções 95:5 e 98:2 (v/v), respectivamente.

A identificação dos analitos na CCD foi realizada por comparação dos padrões analíticos de parabenos, metil e propilparabeno, e o fator de retenção para cada spot.

\subsection{Determinação dos parabenos empregando a titulação potenciométrica}

Após a centrifugação da amostra o sobrenadante foi transferido para um béquer de $150 \mathrm{~mL}$ e adicionou-se $20,0 \mathrm{~mL}$ de uma solução de $\mathrm{NaOH} 0,1 \mathrm{~mol} \mathrm{~L}^{-1}$, anteriormente padronizado com biftalato de potássio. A reação foi mantida por 1 hora a temperatura ambiente. Posteriormente, o volume de $\mathrm{NaOH}$ que não reagiu com os parabenos foi titulado com solução de $\mathrm{H}_{2} \mathrm{SO}_{4}$ $0,5 \mathrm{~mol} \mathrm{~L} \mathrm{~L}^{-1}$, padronizada com carbonato de sódio. As titulações foram realizadas em triplicata $(n=3)$.

\section{Resultados e discussões}

\subsection{Otimização do solvente de extração}

Os produtos cosméticos apresentam-se como uma matriz complexa tendo na sua formulação compostos, tais como: proteínas e gorduras, que podem interferir nas análises. Portanto, o solvente de extração foi avaliado visando uma matriz mais pura e livre de contaminantes. No processo de extração foi avaliado etanol, etanol:água (50:50, v/v) e solução aquosa acidificada (água:ácido acético $1 \%, \mathrm{v} / \mathrm{v}$ ).

Segundo os testes realizados na etapa de extração o uso de etanol $100 \%$ apresentou os melhores resultados. Os parabenos são compostos de média polaridade sendo altamente solúveis em etanol. A solução aquosa acidificada com ácido acético 1\% (v/v) não apresentou resultados satisfatórios, pois promoveu a diminuição do $\mathrm{pH}$ do meio, fazendo com que os parabenos (pka>8) ficassem protonados [13] permanecendo retidos na base da placa, não sendo possível observar a separação na CCD.

\subsection{Otimização da fase móvel para a realização da CCD e identificação dos parabenos}


A otimização da fase móvel para as separações cromatográficas foi uma etapa importante avaliada no desenvolvimento deste trabalho. A mistura, diclorometano e metanol (95:5, v/v), foi primeiramente avaliada como fase móvel (Figura 1A). Nesta condição, observou-se uma separação inadequada dos analitos e spots pouco regulares com formação de cauda (Figura1A). Visando melhorar a separação para identificação dos compostos foi avaliada uma mistura de $\mathrm{CH}_{2} \mathrm{Cl}_{2} / \mathrm{MeOH}$ diminuindo a polaridade da fase móvel $(98: 2, \mathrm{v} / \mathrm{v})$ (Figura 1B).
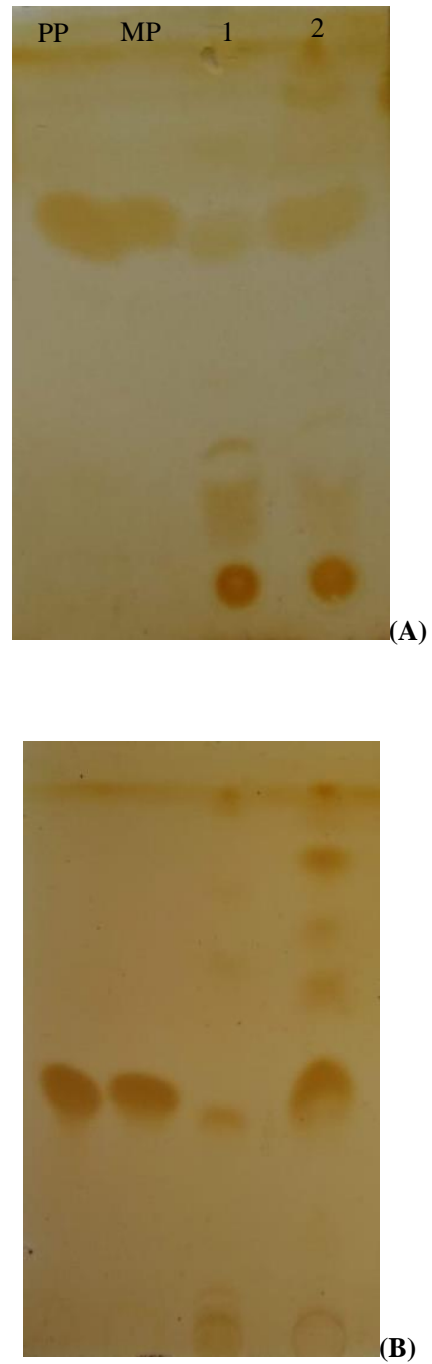

Figura 1: Separação cromatográfica dos parabenos na placa de CCD. A) Eluição com a fase móvel $\left.\mathrm{CH}_{2} \mathrm{Cl}_{2} / \mathrm{MeOH}(95: 5, \mathrm{v} / \mathrm{v}), \mathrm{B}\right)$ Eluição com a fase móvel $\mathrm{CH}_{2} \mathrm{Cl}_{2} / \mathrm{MeOH}(98: 2$, v/v). Solvente de extração etanol 100\%. MP - metilparabeno, PP -propilparabeno, A1 e A2, são as amostras 1 e 2, respectivamente.
Conforme se observou na Figura $1 \mathrm{~B}$, a proporção $\left(\mathrm{CH}_{2} \mathrm{Cl}_{2} / \mathrm{MeOH}(98: 2\right.$, v/v)) resultou em menor polaridade e, consequentemente, melhor separação dos analitos (relativo à altura dos spots na placa) além de manchas com formato mais regular (mais arredondadas).

\subsection{Identificação dos parabenos na placa cromatográfica}

Após otimização da fase móvel, os parabenos foram confirmados empregando-se os padrões analíticos e o fator de retenção dos compostos. Na Figura 2, observa-se uma placa de CCD para os padrões analíticos e todas as amostras avaliadas neste trabalho (A1, A2, A3, A4 e A5). Os spots 1 e 2 na placa são referentes aos padrões, metil e propil-parabeno, respectivamente. Das amostras analisadas neste trabalho, observou-se a presença de metilparabeno (amostra 1), metil e propilparabenos (amostra 2 e 3) e nenhum parabeno foi identificado nas amostras 4 e 5 (Figura 2).

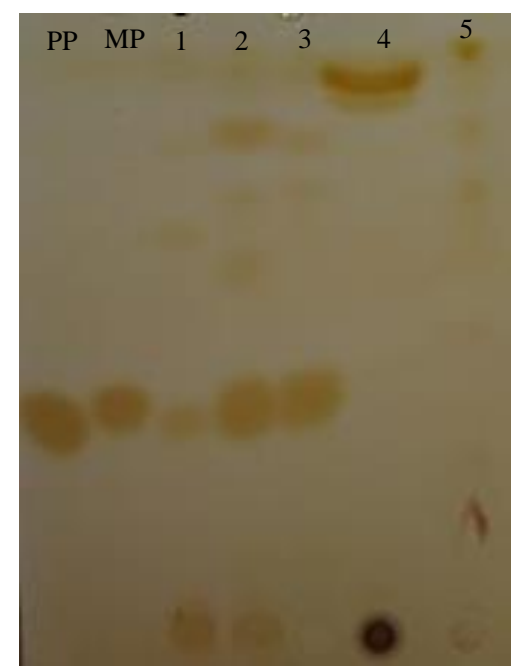

Figura 2: Placa CCD das amostras de cosméticos avaliadas empregando as melhores condições avaliadas na etapa de otimização (eluição com a fase móvel $\mathrm{CH}_{2} \mathrm{Cl}_{2} / \mathrm{MeOH}$ (98:2, v/v) e solvente de extração etanol puro). MP - metilparabeno e PP - propilparabeno. Amostras analisadas: 1, 2, 3, 4, e 5.

Para cada spot calculou-se o fator de retenção, o critério mais importante para este tipo de cromatografia (Tabela 1) [10]. Devido à semelhança estrutural dos parabenos e polaridade muito próxima, metil e propilparabeno, apresentaram valores de $\mathrm{R}_{\mathrm{f}}$ quivalentes não sendo possível a separação destes na placa de CCD. Portanto, quando as amostras de cosméticos contêm ambos parabenos observa-se maior intensidade da mancha na placa (Figura 2). 
Tabela 1 - Fator de Retenção (Rf) calculado para cada spot relativos aos parabenos na placa de CCD.

\begin{tabular}{cc}
\hline Amostras & Rf \\
\hline MP & 0,37 \\
PP & 0,37 \\
$\mathbf{1}$ & 0,36 \\
$\mathbf{2}$ & 0,37 \\
$\mathbf{3}$ & 0,37 \\
$\mathbf{4}$ & --- \\
$\mathbf{5}$ & --- \\
\hline
\end{tabular}

A comparação do fator de retenção dos padrões metil e propilparabeno com aqueles encontrados nas amostras de cosméticos analisadas permitiu a identificação dos analitos.

3.4 Quantificação dos parabenos empregando a titulação potenciométrica e o método da segunda derivada

Para quantificação de parabenos efetuou-se a titulação potenciométrica, técnica preconizada para quantificação dos parabenos em matérias primas pela Farmacopeia Brasileira [11]. Para esta modalidade de titulação, a cada volume do titulante adicionado foi medido o pH da solução com o uso de um pHmetro. No final das titulações, construiu-se a curva de titulação= Através, do software Origin foi possível fazer o cálculo da derivada $2^{\mathrm{a}}$, determinando-se o volume exato de $\mathrm{H}_{2} \mathrm{SO}_{4}$ no ponto de equivalência. Para determinar a concentração de parabenos, foi realizada a titulação do branco em triplicatas $(n=3)$.]

A Figura 3 ilustra os gráficos das derivadas obtidas a partir da construção das curvas de titulação $\left(\mathrm{H}_{2} \mathrm{SO}_{4}(\mathrm{~mL})\right.$ versus $\mathrm{NaOH}(\mathrm{mL}))$.

Curva de titulação: $\mathrm{H}_{2} \mathrm{SO}_{4} \times \mathrm{NaOH}$ (amostra 3)

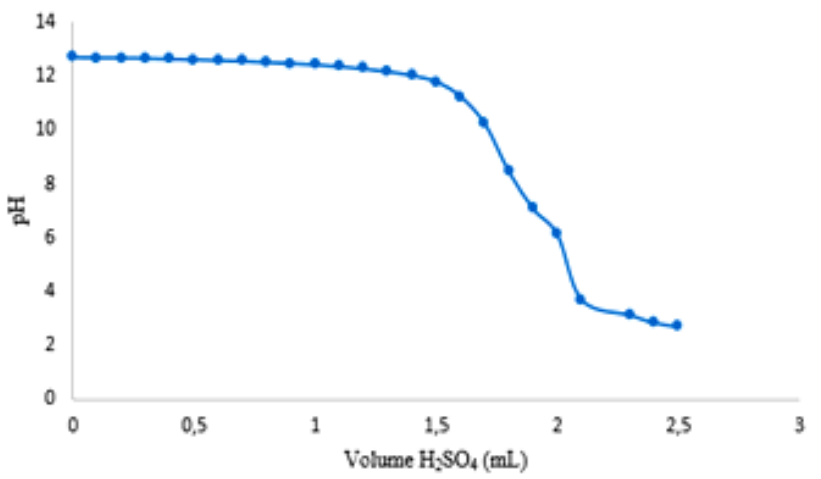

(A)

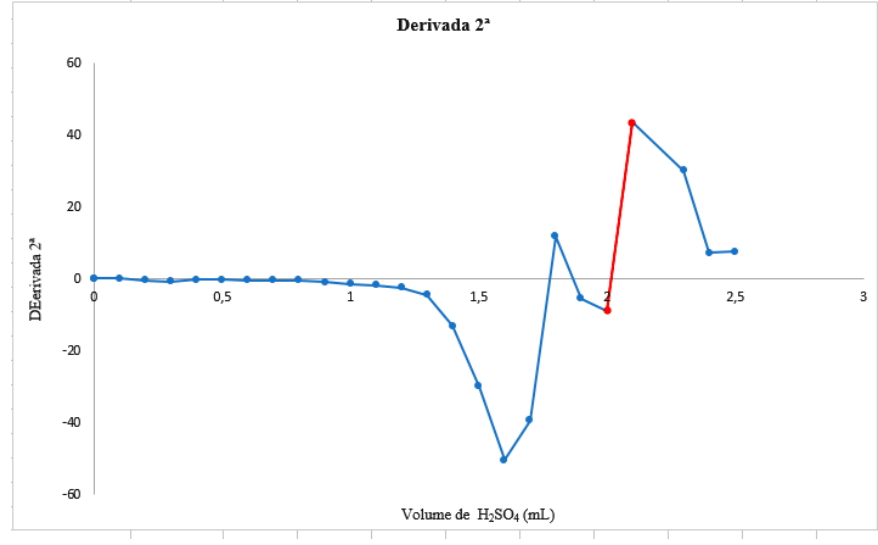

(B)

Figura 3: A) Curva de titulação empregando $\mathrm{H}_{2} \mathrm{SO}_{4}$ e $\mathrm{NaOH}$ para a amostra 3; B) Derivada $2^{\mathrm{a}}$ da titulação potenciométrica, do $\mathrm{H}_{2} \mathrm{SO}_{4}$ e o excesso de $\mathrm{NaOH}$, referente amostra 3.

Através dos gráficos da derivada $2^{\mathrm{a}} \times$ Volume de $\mathrm{H}_{2} \mathrm{SO}_{4}$ foi possível encontrar a equação da reta na $2^{\mathrm{a}}$ inflexão do gráfico, representado em vermelho. Ao encontrar o valor de " $\mathrm{x}$ " quando "y" é igual à zero, é determinado o volume de $\mathrm{H}_{2} \mathrm{SO}_{4}$ no ponto de equivalência. Na Tabela 2 são apresentados os valores encontrados para o volume de $\mathrm{H}_{2} \mathrm{SO}_{4}$ no ponto de equivalência, desvio padrão das triplicatas e o coeficiente de variação $(\mathrm{CV})$.

O coeficiente de variação obtido foi menor que 5,0\% para todas as análises, assegurando uma boa precisão analítica. Estes valores são significativos quando comparados a outros trabalhos descritos na literatura empregando técnicas sofisticadas como HPLC/UV [8,14].

Tabela 2 - Valores encontrados para o volume de $\mathrm{H}_{2} \mathrm{SO}_{4}$ no ponto de equivalência, desvio padrão das triplicatas e o coeficiente de variação (CV).

\begin{tabular}{cccc}
\hline Amostras & $\begin{array}{c}\text { Média dos } \\
\text { volumes }(\mathbf{m L})\end{array}$ & $\begin{array}{c}\text { Desvio Padrão } \\
\text { (SD) }\end{array}$ & $\begin{array}{c}\text { Coeficiente } \\
\text { de variação } \\
(\%)\end{array}$ \\
\hline Branco & 2,03 & 0,031 & 1,5 \\
1 & 1,98 & 0,052 & 2,6 \\
2 & 1,94 & 0.079 & 4,1 \\
3 & 1,96 & 0,036 & 1,8 \\
\hline
\end{tabular}

3.5 Determinação da concentração dos parabenos nas amostras de cosméticos avaliadas

A reação do parabeno comNaOH ocorre na proporção 1: 2. Logo, $2 \mathrm{n}$ de mol de $\mathrm{NaOH}=\mathrm{n}$ de mol de parabenos, através da formula da molaridade, $\mathrm{C}=\mathrm{n} / \mathrm{V}$, onde $\mathrm{C}$ corresponde a concentração, $\mathrm{n}$ ao número de mol e $\mathrm{V}$ ao volume, encontrou-se o número de mol de $\mathrm{NaOH}$ consumido pelos parabenos.

Cálculos efetuados para a amostra 1 como exemplo. 
$\mathrm{V}_{\text {consumido de } \mathrm{NaOH}}=\mathrm{V}_{\text {branco }}-\mathrm{V}_{\text {consumido pela amostra }}$

$\mathrm{V}_{\text {consumido de } \mathrm{NaOH}}=19,14 \mathrm{~mL}-18,67 \mathrm{~mL}$

$\mathrm{V}_{\text {consumido de } \mathrm{NaOH}}=0,47 \mathrm{~mL}$ ou $4,7 \times 10^{-4} \mathrm{~L}$

$\mathrm{C}_{\mathrm{NaOH}}=\underline{\mathrm{n}} \longrightarrow \mathrm{V}_{\mathrm{NaOH}}$ consumido $\mathrm{X} \mathrm{C}_{\mathrm{NaOH}}$

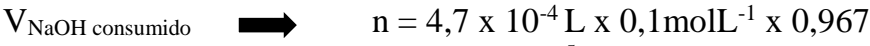

$\mathrm{n}=4,54 \times 10^{-5} \mathrm{~mol}$

Uma que vez que a proporção estequiométrica de parabenos e $\mathrm{NaOH}$ é 1:2, sabe-se que o número de mol de parabenos presente na amostra é igual a metade do número de mol de $\mathrm{NaOH}$ consumido. Sendo a massa molar do metilparabeno igual a $152,2 \mathrm{gmol}^{-1}$, logo, a concentração determinada na amostra 1 foi 3,46 mg de metilparabeno para $1,0 \mathrm{~g}$ de amostra. A Tabela 3 apresenta as concentrações de parabenos determinadas nas amostras de cosméticos em $\mathrm{mg} \mathrm{g}^{-1}$.

Tabela 3 - Concentração $\left(\mathrm{mg} \mathrm{g}^{-1}\right)$ de parabenos nas amostras selecionadas.

\begin{tabular}{ccc}
\hline $\begin{array}{c}\text { AMOSTRAS } \\
\text { AVALIADAS }\end{array}$ & $\begin{array}{c}\text { PARABENOS } \\
\text { IDENTIFICADOS }\end{array}$ & $\begin{array}{c}\text { CONCENTRAÇÃO } \\
\text { DETERMINADA(mg g }\end{array}$ \\
\hline 1 & MP & \\
\hline 2 & MP e PP & 3,46 \\
3 & MP e PP & 7,32 \\
4 & & 5,75 \\
5 & Ausente & - \\
& & -
\end{tabular}
* (para mistura dos compostos nas amostras os resultados são expressos como
propilparabeno); $\mathrm{MP}=$ metilparabeno, $\mathrm{PP}=$ propilparabeno.

De acordo com os resultados obtidos (Tabela 3), observou-se que as concentrações determinadas nos produtos cosméticos avaliados estão abaixo do limite máximo permitido pela ANVISA, ressaltando que para mistura de dois ou mais parabenos o limite máximo permitido é $0,8 \%(\mathrm{~m} / \mathrm{m})$ e para um único tipo de parabeno o limite máximo permitido é $0,4 \%(\mathrm{~m} / \mathrm{m})$, ou seja, $8 \mathrm{mg} \mathrm{g}^{-1}$ e $4 \mathrm{mg} \mathrm{g}^{-1}$, respectivamente.

\section{Conclusão}

O Brasil destaca-se como quarto maior consumidor de cosméticos do mundo de acordo com a Associação Brasileira da Indústria de Higiene Pessoal, Perfumaria e Cosméticos (ABIHPEC). Neste trabalho, foi desenvolvido um método para análise de parabenos (metil e propilparabeno) em amostras de produtos cosméticos comerciais.
A extração dos parabenos foi avaliada tendo em vista a complexidade da matriz. O etanol100\%foi selecionado como melhor solvente de extração para as análises. A CCD foi empregada para identificação dos parabenos sendo confirmada a presença destes compostos pela comparação com os padrões analíticos (metil e propilparabenos). A melhor fase móvel e proporção avaliada na eluição cromatográfica foi 98:2 (v/v), diclorometano/metanol, respectivamente.

O método desenvolvido apresentou boa precisão analítica permitindo a quantificação dos analitos na matriz. Dentre as amostras analisadas pela $\mathrm{CCD}$, duas não apresentaram parabenos, o que estáde acordo com o descrito na composição do rótulo. As demais amostras avaliadas apresentaram parabenos em concentrações ( $\mathrm{mg} \mathrm{g}^{-1}$ ) que ficaram dentro das normas da ANVISA tanto para a adição de um parabeno ou misturas (metil e propilparabenos).

Este trabalho apresentou como vantagens a possibilidade do uso de técnicas simples (cromatografia em camada delgada e titulação potenciométrica) e debaixo custo quando comparada à técnica de CLAE.

\section{ANALYSIS OF PARABENS IN COSMETIC PRODUCTS USING THIN LAYER CHROMATOGRAPHY AND POTENTIOMETRIC TITRATION}

\section{ABSTRACT}

Parabens are chemical preservatives used in several products, including cosmetics. These compounds increase the useful lifetime of products and prevent the development of fungi and bacteria. They can be added individually or in mixtures, increasing the activity against the action of pathogenic microorganisms. The use of parabens in cosmetic products needs to be monitored due to its lipophilic character, which in high concentrations can accumulate in the tissues of the body or induce allergic dermatites. In order to ensure consumer safety, this work aimed to analyze parabens in cosmetic samples using thin layer chromatographic and potentiometric titration. The eluent used was dichloromethane: methanol (98: 2, v/v). For sample preparation, a solid-liquid extraction has been performed. Different solventes were tested in this step: $100 \%$ etanol, etanol: water $(50: 50, \mathrm{v} / \mathrm{v})$ and acidified aqueous solution (water: acetic acid $1 \%$, v/v). Potentiometric titration was performed using digital $\mathrm{pH}$ meter and $\mathrm{H}_{2} \mathrm{SO}_{4}$ as titrant. Five samples were analyzed. According to the obtained results, two samples did not contain any preservatives, one contained only methylparaben and two contained methyl and propylparabens. It was also possible to conclude that parabens concentrations were within the recommended values by ANVISA. The method showed inter-assay precision (variation coefficient) 
less than $5.0 \%$ for all samples. Therefore, the developed method proved to be a simple and accessible tool which uses small volume of organic solvent and can be applied in quality control of methyl and propyl-parabens in cosmetic products.

Keywords: Cosmetics. Parabens. Chromatography. Titration. Preservatives.

\section{Referências}

[1] - MATWIEJCZUK, N., GALICKA, A., BRZÓSKA, M.M., Review of the safety of application of cosmetic products containing parabens,J. Appl. Toxicol., $2020,40,176$

[2] - SONI, M, I. G. Safety assessment of esters of p-hydroxybenzoic acid (parabens), Food and Chem. Toxicol., 2005, 43, 1015.

[3] - HANDA, O., Methylparaben potentiates UV-induced damage of skin keratinocytes, Toxicol., 2006, 227, 72.

[4]- ROUTLEDGE, E.J., PARKER, J., ODUM, J., ASHBY, J., SUMPTER, J.P. Some alkyl hydroxy benzoate preservatives (parabens) are estrogenic, Toxicol. And Applied Pharmacol., 1998, 153, 19.

[5] - DARBRE, P.D., ALJARRAH, A., MILLER, W.R., COLDHAM, N.G., SAUER, M.J., POPE. GS. Concentrations of parabens in human breast tumours, J. of Applied toxicol., 2004, 24, 13.

[6] - SPADOTO, MARIÂNGELA. Tese de Doutorado, Escola de Engenharia de São Carlos, Universidade de São Paulo, São Carlos, SP, Brasil, 2017.

[7] - MELO, LIDERVAN DE PAULA., Tese de Doutorado, Universidade de São Paulo, Ribeirão Preto, SP, Brasil, 2012

[8] - DERISSO, C.R., dissertação de Mestrado, Universidade de São Paulo, São Carlos, SP, Brasil, 2017.

[9] - COLlinS, C., BRAGA, G., BONATO, P., Introdução a métodos cromatográficos. $5^{\text {a }}$ ed. Campinas: Editora da Unicamp, 1993.

[10] - DEGANI, A. L., CASS, Q., VIEIRA, P.,Cromatografia um breve ensaio, Quím. Nova na Escola, 1998, 25.

[11] - COMISSÃO PERMANENTE DE REVISÃO DA FARMACÓPEIA BRASILEIRA. Farmacópeia Brasileira. Parte II, fascículo 3. $4^{\mathrm{a}}$ edição. Editora Atheneu. São Paulo, 2002.

[12] - OLIVEIRA, M., LIMA, E.M., Anais eletrônicos do III Seminário de Pesquisa e Pós-Graduação/ III CONPEEX, Goiânia: UFG, Brasil, 2006.

[13] -ANGELOV, T., VLASENKO, A., TASHKOV, W.,J. Liq. Chrom. Relat. Tech, 2007, 31, 197.

[14] - MELO, L.P., QUEIROZ. M.E.Q., Simultaneous analysis of parabens in cosmetic products by stir bar sorptive extraction and liquid chromatography, J. of Sep. Sci. 2010, 33, 1855. 